\title{
Children's Savings Account Programs Enable Parents to Plan and Talk about College with Children and others
}

\author{
William Elliott*, Briana Starks, Kristen Seefeldt, James Ellis \\ School of Social Work, University of Michigan, Ann Arbor, MI, USA \\ Email: *willelli@umich.edu
}

How to cite this paper: Elliott, W., Starks, B., Seefeldt, K., \& Ellis, J. (2018). Children's Savings Account Programs Enable Parents to Plan and Talk about College with Children and others. Sociology Mind, 8, 345-365. https://doi.org/10.4236/sm.2018.84022

Received: August 8, 2018

Accepted: October 27, 2018

Published: October 30, 2018

Copyright (C) 2018 by authors and Scientific Research Publishing Inc. This work is licensed under the Creative Commons Attribution International License (CC BY 4.0).

http://creativecommons.org/licenses/by/4.0/

\begin{abstract}
The researchers adopted a positivist approach to qualitative research, hypothesizing that the interviews would reveal positive parental expectations and development of college-saver identity among Harold Alfond College Challenge (HACC) participants. HACC is an opt-out children's savings account asset intervention that begins at birth for children born in Maine. For this study, data were obtained through structured interviews of 22 families. Most parents in HACC describe having positive educational expectations and having developed a college-saver identity. More research is needed.
\end{abstract}

\section{Keywords}

Children's Savings Accounts (CSAs), College, College-Saver Identity, Educational Expectations, Identity-Based Motivation, Saving

\section{Introduction}

Children's savings accounts (CSAs) are interventions that aim to equip children with assets (Sherraden, 1991) and cultivate the development of identities consistent with educational attainment. In many cases, including in Maine's Harold Alfond College Challenge, children receive CSAs at birth. This timeline takes advantage of the longer period of asset accumulation to build balances and influence children's development (Sherraden, 1991). CSAs are often capitalized with an initial deposit and augmented by transfers in the form of benchmark incentives and savings matches (Goldberg, 2005; Loya, Garber, \& Santos, 2017; Sherraden, 1991).

CSAs are gaining traction around the country as more policymakers, philanthropists, and educators become concerned about the high cost of education, 
rising student debt, and the declining fortunes of America's youth. At the end of 2016, nearly 313,000 children had a CSA in one of 42 programs operating in 29 states, a 39\% increase in enrollment from the previous year (CFED, 2016). Maine's Harold Alfond College Challenge (HACC), the subject of this study, is a leader in the CSA field, recognized as one of the oldest and most prominent CSAs in the country.

\section{Harold Alfond College Challenge Program Description}

Harold Alfond College Challenge (HACC) leverages the state's 529 plan, NextGen, as a platform for delivering their CSA program. Authorized in the Internal Revenue Code since 2001 and named after the section of the tax code that created them, 529 plans are tax-preferred vehicles for post-secondary education saving. They are administered by states, usually through contractual agreements with private financial institutions (Boshara, Clancy, Newville, \& Sherraden, 2009; Clancy, Lassar, \& Taake, 2010). HACC offered an initial $\$ 500$ grant to every Maine resident infant for whom a NextGen 529 college savings account was opened by the baby's first birthday.

In addition to providing these seed deposits, the Alfond Scholarship Foundation also invested heavily in outreach to make Mainers aware of the initiative, targeting parents in hospitals and birth classes (Harold Alfond Foundation, 2011; 2012) and working with pediatricians' offices, educational institutions, businesses, and nonprofit organizations (Clancy \& Sherraden, 2014). The Alfond Foundation estimates that during the first six years, they spent approximately $85 \%$ of their total non-grant investment funds on this outreach and engagement (C. Quint, personal communication, March 31, 2015). Despite these efforts, research by the Center for Social Development found that gaps in awareness of HACC persisted, with less financially sophisticated parents less likely to complete the required account opening (Huang et al., 2013). As a result, under the opt-in design, 23,000 Maine babies were enrolled, for an uptake rate of approximately $40 \%$. This compared favorably to the $4 \%$ of Maine families with a NextGen account prior to HACC (Harold Alfond Foundation, 2013) but was still short of desired participation rates. These findings and a desire to increase efficiency contributed to a shift to universal, opt-out enrollment, where Maine residents with a newborn baby are automatically enrolled in HACC using birth records (Powell, 2014). Today, Maine families receive notice of the HACC award around one month after their child's birth and information on opening a NextGen account at their child's first birthday (Clancy \& Sherraden, 2014). The $\$ 500$ HACC grants are automatically deposited into an omnibus account and belong to the Alfond Scholarship Foundation until disbursement to a postsecondary educational institution (Clancy \& Sherraden, 2014).

While the money for the $\$ 500$ HACC grants comes entirely from the Harold Alfond Foundation, FAME is an important partner, acting as the administrator of the 529 plan and facilitating data sharing. FAME also augments children's as- 
set holdings by providing NextStep matches for NextGen accounts opened on or after January 1, 2011, that have received at least $\$ 50$ in contributions in the calendar year. Maine families can get a 50\% match, automatically deposited for qualifying contributions, up to a maximum annual match of $\$ 300$, with no lifetime limit (Finance Authority of Maine, 2015) or income threshold (Clancy \& Sherraden, 2014). In addition, NextGen accounts set up with automatic deposits are eligible for a one-time additional $\$ 100$ match from FAME. Families who contribute to NextGen accounts may also benefit from federal tax advantages associated with $529 \mathrm{~s}$.

\section{Literature Review}

Parental educational expectations are about more than just parents' beliefs about what their children's future may hold; such expectations may have tangible effects on children's actual prospects. Specifically, parental educational expectations have been shown to be an important factor for predicting children's academic achievement in school and their college enrollment rates (Marjoribanks, 1984; Zhan, 2006). Research suggests most parents (64\%) expect their child to complete a 4-year degree (Child Trends Data Bank, 2015). However, when the data are disaggregated, only about half of parents with annual incomes of less than $\$ 30,000$ expect their child to complete a 4-year degree (Child Trends Data Bank, 2015). Again, these differences may have concrete implications for children's later educational attainment. Researchers have linked parental education expectations with children's academic achievement and later college enrollment (Davis-Kean, 2005; Englund, Luckner, Whaley, \& Egeland, 2004; Pearce, 2006; Zhang, Haddad, Torres, \& Chen, 2011). Hess, Holloway, Dickson and Price (1984) found that a mother's expectations of her preschool child are positively linked to the child's proficiency in sixth-grade math and vocabulary. Entwisle, Alexander and Olson (2005) found that lower expectations may translate into a reduced chance of low-income children completing college. These effects are likely realized through multiple channels, including parental engagement and investment in children's schooling (Gill \& Reynolds, 1999; Singh et al., 1995). Importantly, low expectations can be transmitted from parent to child (Sandefur, Meier, \& Campbell, 2006; Singh et al., 1995), which suggests that disparities in educational expectations can influence low-income children's educational outcomes.

Parent expectations in the form of discussing academic requirements, college costs, and providing financial support to adolescents in middle school and high school can influence college expectations. Analyzing data from a national survey, students who discussed academic requirements for college admission, specific colleges they were planning to attend, and financial options and costs of attending college with parent from high socioeconomic backgrounds was associated with higher college aspirations and were more certain of their college plans (Horn, Chen, \& Chapman, 2003; Hossler, Schmit, \& Vesper, 1999). Additionally, 
Horn (2003) found that the likelihood of parents reporting they had begun saving or making other financial preparations increased with household income. Furthermore, Horn (2003) found that as students' GPA increased so did parents' financial saving for college, seeking information about financial aid, and acquiring knowledge about education tax credits. On the other hand, Rowan-Kenyon, Bell and Perna (2008) found in their qualitative study that low SES parents conveyed to students to expect that they would have to fully pay for college.

\section{CSAs' Relationship to Parental Educational Expectations}

Asset researchers have consistently found that having assets can enhance what parents and their children expect for their future. For example, Zhan and Sherraden (2011) used the National Longitudinal Survey of Youth to establish a temporal order between assets, educational expectations, and children's college graduation. This early study helped to affirm the theoretical foundation of asset-based social welfare, specifically that assets work differently than income to influence perceptions, motivation, and behavior (Sherraden, 1991). Using experimental data from the SEED for Oklahoma Kids CSA experiment, Kim, Sherraden, Huang and Clancy (2015) directly examined the impact of CSAs on the durability of parents' educational expectations from birth to age four. They found that parents whose children received the CSA had higher expectations for their children's future education and that their expectations were more likely to remain constant or increase than parents whose children did not receive the CSA. In a follow-up study, Kim, Huang, Sherraden and Clancy (2017) examined whether opening a parent-owned 529 college savings plan account in order to save alongside the SEED OK account mediated the relationship between CSA treatment and parental expectations. Findings from this study indicated that 1) SEED OK treatment has a positive and significant causal effect on parental expectations, and 2) parents who open their own 529 college savings plan account have higher expectations than those who do not. Further, receiving the SEED OK CSA positively affected caregivers' likelihood of opening an account to save for their child's education. In tracing CSAs' effects on parental expectations to their encouragement of early educational account ownership, this research provides further evidence of the importance of institutions in shaping how families see their future. It also helps to frame the pathways through which a CSA intervention such as the Harold Alfond College Challenge may alter parents' expectations for their children, which, in turn, may affect their preparations for their expected future.

\section{Theory}

Some researchers in the CSA field have used educational expectations as a proxy for whether or not a parent or child has formed a college-saver identity (Elliott, 2013; Oyserman, 2013). However, in most secondary studies using national data sets, due to data limitations, parental educational expectations are measured 
simply by asking whether or not parents expect their child to attend college (yes/no or Likert scale). However, just because someone identifies their child as being collegebound (i.e., expecting to attend) does not mean their expectations will be predictive of their actions. Research on wilt illustrates this point (Elliott \& Beverly, 2011). Wilt occurs when children who expect to attend college while in high school and are meeting academic requirements do not attend college when they reach college age (Elliott, 2011). Identity-based motivation (IBM) theory posits that people form many identities (i.e., possible selves), such as being collegebound, but they do not act on them all (Oyserman, 2007; Oyserman, Bybee, \& Terry, 2006; Oyserman \& Destin, 2010). Using the IBM framework then, educational expectations are a type of possible-self or identity composed of different dimensions shown to be predictive of people's behavior (Oyserman et al., 2006). In line with this, in this study, the dimensions of educational expectations and the ways parents express the mare examined, whether parents expect their child to attend college or not.

\subsection{Three Dimensions of Parental Educational Expectations}

There are three principal dimensions of IBM proposed by Oyserman and colleagues that may help us better understand the relationship between the HACCand parental educational expectations: 1) identity salience, 2) interpretation of difficulty as normal, and 3) congruence with other, held group identities (Oyserman \& Destin, 2010). Salience captures the idea that children are more likely to work toward a goal when images of their own future are at the forefront of their mind and when this future seems more proximate than distant. The concept of interpreting difficulty as normal captures the idea that in order for children to sustain effort and work towards an image of themselves as being collegebound, the context must provide a way to address inevitable obstacles to the goal of attending college, such as college financing. Finally, congruence with group identity occurs when an image of the self feels tied to ideas about relevant social groups such as friends, classmates, family, and cultural groups. When this occurs, the congruent personal identity is reinforced.

When parents display all three dimensions, we understand their college-saver identity to be the type that people act on (Elliott, 2013; Oyserman, 2013; Oyserman et al., 2006; Oyserman, Terry, \& Bybee, 2002). This takes the analysis from simply examining parents' explicit expressions of their expectations that their child(ren) will attend college to consideration of the following:

- Salience, or whether they talk about college with their children,

- Difficulty as normal, or whether they talk about saving as a way to help pay for college, and

- Group congruence, or whether they convey the idea to their children (and even other parents) that people like them also save and go to college.

While the college-saver identity is usually discussed in reference to children,

Elliott (2015) has suggested that parents may also form a college-saver identity 
when they identify assets as a strategy for helping their child pay for college and perceive that their child is college bound. As posited here, it is possible for parents to see themselves as college savers even if the savings result not from the act of saving but from a transfer (e.g., the initial $\$ 500$ grant provided by HACC) or from just having an account. Moreover, it is posited that CSA programs like HACC can affect parents' engagement in shaping their child(ren)'s formation of their own college-saver identity. That is, parents' college-saver identities are not just about parents' engagement with saving but also about their engagement in their child(ren)'s formation of a college-saver identity.

\subsection{College-Going Culture}

According to the IBM model, acting on a college-saver identity is linked to the context in which parents and their children experience this identity. (See Oyserman \& Destin, 2010, for the importance of context within the IBM model.) The Center on Assets, Education, and Inclusion has referred to this context as a college-going culture (Elliott, 2015). A college-going culture emerges when people in a particular place or participants in a given CSA program begin to identify with the CSA as a type of group identity around saving and going to college. Therefore, parents' recruitment of others to enroll in a CSA or to save once enrolled, even in a universal and automatic CSA design, may be evidence of a college-going culture.

\section{Methods}

\subsection{Data Sources and Instrumentation}

The Internal Review Board of the University of Michigan approved this study. Structured interview guides were used to collect qualitative data from 22 parents whose children received the HACC. Interviewees also filled out demographic forms that included questions on household circumstances, savings behavior, parent employment, hopes and expectations for children's education, and expectations about college costs. Table 1 describes the demographic make-up of the sample.

The children in the sample are predominantly white. They range from Pre-K to fifth grade. Sixty-eight percent of parents in the sample are married. A large proportion are highly educated; $43 \%$ of the parents who filled out the survey have a graduate degree and $33 \%$ have a 4 -year degree. The median household income for Maine in 2016 was \$53,079 (Department of Numbers, 2017). A total of $35 \%$ of the households have incomes of $\$ 59,999$ or less; $24 \%$ have incomes of $\$ 100,000$ or higher.

Final Sample

With regard to the structured interviews, one parent refused to be audio recorded and three interviews with faulty audio recordings were eliminated prior to analysis, leaving 18 interviews. All participants were informed of the possible 
Table 1. Demographic Profile of Sample $(\mathrm{N}=22)$.

\begin{tabular}{|c|c|c|}
\hline Variable Name & Freq & Percent \\
\hline \multicolumn{3}{|l|}{ Child 1 Grade } \\
\hline Pre-K & 2 & 10 \\
\hline $\mathrm{K}$ & 2 & 19 \\
\hline $1^{\text {st }}$ & 4 & 19 \\
\hline $2^{\text {nd }}$ & 4 & 14 \\
\hline $3^{\text {rd }}$ & 3 & 5 \\
\hline $5^{\text {th }}$ & 7 & 33 \\
\hline \multicolumn{3}{|l|}{ Race } \\
\hline White & 20 & 90 \\
\hline Black/African American & 2 & 10 \\
\hline \multicolumn{3}{|l|}{ Household Income } \\
\hline$\$ 10,000$ - \$14,999 & 1 & 5 \\
\hline$\$ 20,000-\$ 29,000$ & 1 & 5 \\
\hline$\$ 30,000-\$ 39,000$ & 2 & 10 \\
\hline$\$ 40,000-\$ 49,000$ & 1 & 5 \\
\hline$\$ 50,000$ - $\$ 59,999$ & 2 & 10 \\
\hline$\$ 60,000-\$ 74,999$ & 4 & 19 \\
\hline$\$ 75,000-\$ 99,999$ & 5 & 24 \\
\hline$\$ 100,000-\$ 149,999$ & 4 & 19 \\
\hline$\$ 150,000$ or more & 1 & 5 \\
\hline \multicolumn{3}{|l|}{ Marital Status } \\
\hline Married & 15 & 68 \\
\hline Widowed & 1 & 5 \\
\hline Separated/Divorced & 3 & 14 \\
\hline Never Married & 3 & 14 \\
\hline \multicolumn{3}{|c|}{ Highest Level of Education Parent Completed } \\
\hline GED & 1 & 5 \\
\hline Some College & 2 & 10 \\
\hline 2-Year Degree & 2 & 10 \\
\hline 4-Year Degree & 7 & 33 \\
\hline Graduate School & 9 & 43 \\
\hline
\end{tabular}

benefits and risks of participation and signed consent forms. All of the analyzed interviews were audio recorded with the participant's permission. Interviews with parents generally lasted between 30 and 40 minutes. A contracted transcription company transcribed all interviews.

\subsection{Data Analysis}

The research team used sensitizing concepts (Padgett, 2008; Patton, 2002) from 
the main sections of the interview guides and the main components of IBM theory to develop an initial code list. Four researchers coded the transcripts. Memos were made when coders were unsure of the fit between the code list and the interview content. Those memos were reviewed by three team members, and coding discrepancies were resolved through dialogue. Padgett (2008) and Patton (2002) agree that the quality of qualitative research tends to be questioned, particularly by those unfamiliar with the rigor involved in qualitative inquiry, methods, and analysis. Rather than using words such as reliability and validity, which are suited to quantitative studies, qualitative researchers often use the term trustworthiness, which consists of four components: credibility, auditability (or dependability), confirmability, and transferability (Padgett, 2008).

The researchers adopted a positivist approach to qualitative research. We hypothesized that the interviews would reveal a pre-existing theoretical model. By analyzing in teams, interviewing parents and children, and gathering information from the parent demographic form, the research team was able to triangulate data to enhance confirmability. Extensive written documentation, including notes from interviews and analysis meetings, memos from the coding process, and process notes from analysis, further support confirmability. The research team worked together to keep the findings in context in order to enhance the transferability of findings and implications from this qualitative research.

\section{Results}

\subsection{Parental Educational Expectations}

Most (56\%) families' responses in the in-depth interviews suggest that they expect their child to graduate from high school and go on to get some form of postsecondary education. In many cases, these expectations are seen as consistent with the parent's own educational attainment. Speaking about her expectations for her children, Heather, a middle-class teacher, said, "I want them for sure to get a bachelor's degree. I don't think that's in question."When speaking about her expectations for her son, Martha, a high-income mother of two, said, "I'm a second-generation university graduate so I just expect that he's going to pick up and follow that line as well." Lisa, a school psychologist with an advanced degree, expects her children to go beyond a 4-year degree:

I will expect them to at least have to have a college degree at a bachelor's level. It really depends on what they decide they want to do right now. One of my daughters wants to be a doctor so obviously, [if] she continues on that then she'll have to go on to medical school. My other daughter wants to be a school psychologist like myself, so she will have to also go on to graduate school. We are thinking about it not just being a 4-year degree at this point but having to look beyond that."

However, not all parents expect their child to attend a 4-year college; rather, they expect them to go on to get some kind of schooling after high school. For 
example, Liz, who completed some college credits and works in sales, earning a middle-class income, spoke about her youngest daughter, saying, "I don't think it [school] comes as easy to her, but she's still a very bright child and she studies very well and I see her going to college. Ideally, I'd like to see her go to a 4-year college, but anything would be good. I'd like her to continue her education after high school." Teacher Heather's experiences with college debt make her feel as though going beyond a 4-year degree might not payoff for her children: "I don't want my children to be in debt. We'll do as much as we can to make this possible for them, so they can feel a little freer in their 20s than I felt. For me, it's like the going to college is going to happen no matter what. What will happen after college and how much debt they'll incur is really the question."

However, not all parents who attended college express clear-cut expectations for their child(ren) to follow in their footsteps. For two parents, the young age of their children made it difficult for them to be certain. For example, Tammy a divorced, unemployed low-income mother with a two-year college degree, stated on one hand that she expects her children to attend college: "Well, I wanna see them both go to college, get a good education in whatever career they wanna pursue, so that they are successful, and they can make sure they're able to financially take care of themselves."At the same time, she expressed uncertainty about her children being old enough to value college at this point: "No, my 10-year-old definitely has-we've spoken about college at one point. That's her destination. I was gonna work myself. She'll have the same concept. I'm sure she'll come around. It's just right at that age, they just wanna play in school." When speaking about her 7-year-old, she said, "My youngest one, right now she's 7, so she's, like, I don't wanna go to college. But the conversation I have with her is, 'Well, you know, that's what most people do. You go to college, and you're gonna need to, and you'll change your feelings about that when you get older."'

\section{Weak Expectations that Child(ren) will Attend College}

Out of the nine parents who went to college themselves, less than half (40\%) expressed clear expectations for their children to attend college. In the current context of high college costs and uncertain post-college prospects, parents' consideration of the environment and their own experiences with college debt may create uncertainty in the minds of some parents about whether there are other paths with an equal or better chance of delivering on financial health in adulthood for their children.

Susan, a lower-middle-class teacher, is a good example of a parent who expects her son to go to college but because of the current higher education environment she is unsure education is the only path or even the best path for her son:

I try to be open minded because sometimes, it's really easy to just be like,

"Well, of course you're going to graduate from high school and go on to college," like I think as long as our son is under our roof, like the expectation is you go to high school and then after high school, I think I'm trying 
to be a little more open minded because I know a lot of tech programs are really great now and people are doing alternatives to college that actually provide them with a decent income and so talking to him about his future goals, what he wants to do, and how he's going to get to those goals.

In order to understand Susan's rationale, it is important to note that higher education has not led to a financial windfall for her. Susan's current annual household income is between $\$ 50,000$ and $\$ 59,999$-right around the median in Maine. The family only has about $\$ 1000$ in savings. Further, her father teaches at a technical training school. She has seen firsthand how technical schools can prepare students for jobs that pay even more than jobs people get with a college degree: "A lot of technical education people are actually making more money than people who do liberal arts education now, and so there might be alternatives that he can look at." She concludes her comments about college as one of many possible paths by saying, "I think we are trying as parents to have the expectation that [child] does the best work that he can and we're happy with that. Not what do we want him to accomplish but ... is he doing the best that he can at it. Trying to give him the freedom to make those decisions but still be diligent in his studies." In line with Susan's skepticism about education's ability to serve as a path to the American dream, we find that $44 \%$ of parents in this study see college as an important path but not the only path for achieving the American dream.

However, despite Susan's uncertainty about college being the best path, and while she has not yet formed a college-saver identity, HACC does seem to be encouraging her to begin planning for college. In talking about HACC, Susan says the following:

I think it's great. I'm really happy that it was something that was offered. It kind of pushed us in the right direction of "yeah, we need to start thinking about this right now" instead of waiting until "oh no, our kid is a freshman in high school. We've got four years." Yeah, it' a great incentive to start thinking about those things right away.

Tiffany, a high-income mother with two 4-year degrees and whose husband has a 2-year degree, is also unsure if her children will attend college. Moreover, like Susan, she thinks college is only one path to success. "Personally," she said, "I'm all for college education, but I also know that it's expensive, and it's not for everyone, and I would rather my kids find something that they enjoy and something that they can be successful at, and I don't think you need to have college education necessarily to do that. So I don't really have an expectation or an aspiration for them."Several things seem to be contributing to her doubt about the importance of college. She indicates that her husband has only some college and a certificate of some sort. So she has seen how not completing a college degree has worked out for her husband. Additionally, she has seen others in her extended family go to high-priced colleges and end up in a lot of debt and unhappy 
with their degree. She said, “What I don't wanna see my kids do is feel the pressure to go to college and end up in a lot of debt or unhappy with a degree that they can't use." Additionally, HACC does not seem to be shifting Tiffany's planning for college much:

Yeah. We don't contribute a lot separately to it, because it is very strict on the fine print about what the money can be used for, so we do have alternative options, and financial options that we plan to pursue, should they decide to go to college. But at a minimum, maybe it will help with supplemental costs, et cetera. It does continue to grow, and by the time they graduate, who knows what the cost of education will be, but, again, associated costs, we'll support and cover some of the fees.

Part of the inability of HACC to make much of a difference on Tiffany's outlook may be her perceived financial position. She said, "And anything helps. I mean you never know what could happen. Today we-five years down the road, we might not be as comfortable as we are now. So any little bit will help moving forward." Her annual household income currently ranges between $\$ 100,000$ and $\$ 149,999$. For Tiffany, saving for retirement is more important to her and her children than saving for college:

Because if we aren't prepared for retirement, then that means that the burden falls on our children, right? So that's a big barrier, too, is always making sure that the priority is that we are making appropriate contributions and appropriately making sure that there's never going to be a point in time where our children need to be responsible for us, whether that's retirement or accidental death, disability and stuff like that.

This is in line with previous research that indicates that CSA effects are weaker among higher-income families (Elliott, Constance-Huggins, \& Song, 2013; Huang, Kim, \& Sherraden, 2016). Researchers have suggested a reason for this might be that resources overall are plentiful in higher-income families, so assets held in CSAs make little independent contribution (e.g., Elliott, Constance-Huggins, \& Song, 2013).

\subsection{College-Saver Identity Results}

This study is not just concerned with whether or not parents expect their children to go to college. It is also concerned with whether or not parents are likely to act on an identity of orienting to a college-bound future for their children and whether or not parents are likely to act on that identity in a way that makes it more likely their children will form their own college-saver identity. According to IBM theory, people are likely to act on their college-saver identity when they demonstrate all three components of a college-saver identity (salience, normalization of difficulty, and group congruence) (e.g., Oyserman \& Destin, 2010). Overall, 13 out of 18 parents (72\%) demonstrated evidence of having formed a college-saver identity. To be classified as having a college-saver identity, parents 
have to demonstrate evidence in all three components. Examples of how families evidenced these three components are provided in the next few sections.

\subsubsection{Salience}

Among the 18 parents examined in this study, 83\% made comments consistent with salience. In this study, identity salience is understood to mean a parent being more likely to work toward the goal of his/her child attending college-including opening a CSA and beginning to save-when images of the child's future self are at the forefront of the mind. In line with this, interviewers looked for statements answering questions like these: Does some aspect of HACC make their child going to college, which is far away, feel close? Do parents talk about how being part of the program has fostered conversations with their child or others about college and/or the child's future? Do parents talk about how they are now planning for their child to go to college? Do they talk about how the program has influenced them to act on their child going to college in some way now? Did HACC change their thinking about college saving as an activity to initiate when their children were young, instead of at some vague point in the future?

Heather, a middle-class college graduate, understands HACC as an opportunity for her to begin talking to her child about college, maybe much earlier than she might have otherwise. "For me," she said, "I think it just means planning early. I think it just means maybe having conversations with my child earlier than maybe I would have. Maybe even earlier than my parents had with me."In addition, she indicates that HACC has not only started her talking with her child about college earlier than she might have otherwise; it has also provided a way for her extended family to begin actively planning for her daughter to be able to go to college. "Yeah," she said, "I think maybe that's what it means and I think it also gets family members involved in a way that they wouldn't have otherwise maybe until that kid is graduating high school. People who wouldn't have contributed and we've already had people contribute just at birthday parties and things like that because they know that we're part of that program, so I feel like it just kind of brings that all together for everyone."

Several parents suggest they would have opened a college savings account even without HACC, but they are not sure they would have done it so early. For example, Roberto, a middle-class father and teacher, said, "Well it certainly started us four years ahead of time. I think we have $\$ 2,000$ in there and that certainly wouldn't have happened at least until probably maybe now and who knows, I mean, I'm not $100 \%$ sure when he gets 5 that that's your first thought, like we have to set up a savings plan for him to go to school." This suggests that HACC is not only helping make college feel close for Roberto but that it has also provided a context for him to act by opening a NextGen account and depositing money sooner than he might have otherwise.

\subsubsection{Normalizing the Difficulty of Paying for College}

In this sample, $78 \%$ made comments consistent with HACC helping to normal- 
ize the difficulty of paying for college in their lives. Normalizing the difficulty of paying for college in this study is interpreted as meaning that the HACC CSA makes the concept of the child attending college feel more attainable to the parent. Usually this is conceptualized narrowly to mean that saving for college is seen by parents as important and not impossible. Therefore, putting effort into saving is meaningful rather than pointless.

Michelle, a divorced, low-income mother with a master's degree, lacks information about some of the details of the CSA but understands that HACC is helping her pay for college. She described HACC as "free money for your child to use and a secondary education, whether it be books or college expense, or something, but it has to be after high school. And you can't touch it until they go to college or some kind of secondary education. I believe it does work for vocational schools, but I'm not sure." She added later in the conversation, "Just having you start-having anyone start thinking about college when they're an infant is a great way to put a little bit here, a little bit there and, hopefully, make sure that they go there."Even teacher Donna, who did not express expectations for her children to attend college, understood the potential of HACC to help pay for college:

Well just, I mean, to me, it was, I knew college was important and I used to work in manufacturing and then switched to teaching, and I knew that having enough money for college was going to be a stretch for three children and when we first started saving for college for my son, it was, I wouldn't say money, but money wasn't tight like it is now because it was one child and we were both working in corporate America. Now, neither one of us are working in corporate America and putting aside money for college is not really realistic, so it was one of those things that was a no-brainer decision.

Kristen, a high school graduate and single middle-class mother, clearly expressed the concept of normalizing the difficulty of paying for college for her daughter:

For me, it means a lot, because I didn't necessarily have any sort of financial foundation to start college with. It was all financial aid and student loans, so I feel to go into your college career having to not worry so much about funding is huge. So for her, she's going to have this little nest egg no matter how big or small or it is at the time, but it's something. I think it's probably an advantage just in the whole mentality behind furthering your education. You have money for it, it makes it a lot easier to make that decision.

This statement suggests that for Kristen, HACC is making saving for college feel important and not impossible.

\subsubsection{Group Congruence}

Among the 18 parents examined in this study, 83\% expressed sentiments con- 
sistent with the construct of group congruence. Congruence with group identity occurs when an image of the self feels tied to ideas about relevant social groups (e.g., friends, family, cultural groups, geographic communities, and participants in a CSA program) (Oyserman \& Destin, 2010). In this study, group congruence refers to parents who 1) know others who see savings as a way to pay for their child's college education; 2) know others saving for their children's college-through HACC or elsewhere; 3) see evidence that others support their children's goals of college attainment; and 4) are actively talking to others about HACC or about the importance of saving for their child's college education.

Because HACC has only been in existence about seven years and children start in the program from birth, many Mainers are not yet participating in HACC. This can reduce the opportunities to identify with others in the program. Despite this, families still show signs of identifying with HACC and the notion that people like them are saving for their children to attend college. For example, in talking about her conversations about HACC with other people, Heather said the following:

Conversations with kids of my class, it has come up before, actually. They're beyond the age of where it's began in Maine and different people, it comes up every once in a while and they don't know what I'm talking about, then I realize, "Oh, your children were not in the band where this began," cause to me it's like I'm so used to being surrounded by people who have kids around the same age and we all have our kids in it and we all sort of know what we're talking about when we say Harold Alfond. We're like, “Oh, we know what you mean."

Similarly, Sadie, a high-income, educated mother who has saved a substantial amount in her children's NextGen accounts, indicated that most of her friends and extended family are not only aware of HACC but are acting on the opportunity. She said, "Most of my conversations have been to friends and family that are expecting, just being like, 'Hey, are you guys aware of this or that this is available?' Most of them have heard about it. If not, they definitely have by the time they've had their children, but I know a lot of them have taken advantage of it as well."

However, not all families express the sense that HACC is something other people like them are participating in. When asked about the kinds of conversations she has had about HACC, Lisa said, "We have actually not had any conversations with anyone, so I have no idea even among my group of friends of who participated and who hasn't." Kate also has not talked to others about HACC. She said, "I don't think I've had any conversations about it with other people." Michelle knows others like her who are participating in HACC. She said, "But most people I know have it. I mean most people are like, yeah, I mean it's free." However, when she talks to some people, they are scared away from the program because of the idea that they might be penalized for putting too much money in the account. "Don't put money in it," she said. "That's the con- 
versation I get from a lot of people. Don't-it's great that you have it. Do invest a lot of your money in it, because financial institutions-colleges will look at that when you fill out the FAFSA, and-which I don't ... that's an international thing, but when you fill that out, and it will count against you."

\subsection{Alignment of Educational Expectations and College-Saver Identity}

\subsubsection{Expecting Child to Attend College but No College-Saver Identity}

Two parents expect their children to attend college but do not demonstrate they have formed a college-saver identity. Jamil, a widowed, low-income black mother who herself is a student in college, expects her children to attend college; however, she recognizes that college is only one path to success. She said, "I just want them to discover themselves. Whatever they like is what I want them to achieve in terms of education." She also demonstrates that she sees HACC as helping her pay for college (difficulty as normal), "I think it's important to start your kids' college fund as early as you can, and as time progresses every penny that goes toward to your kids' school is something that is highly important to every parent." Moreover, there is evidence that HACC is bringing college to the forefront of her mind: "I really think [it] is a wonderful program to remind parents about activities like this." But she also seems to claim that people like her do not save and go to college: "Because $80 \%$ of my people don't consider those activities as early as that age. They wait until last minute, like, 'We're gonna pay $\$ 20,000$ for college tuition?' Whoa!”

For other parents, it is salience, rather than group congruence, that is notably absent in their thinking about higher education. When Liz was asked if she expects her younger daughter to attend college, she said, "Ideally, I'd like to see her go to a 4-year college, but anything would be good. I'd like her to continue her education after high school." But when asked about saving for college, Liz said, "I mean, I wish I could say it was a giant priority, but paying our bills and making sure our children have food on the table and clothes and they are participating in the sports they want to play. That's more important to us right now. We're not really thinking about college yet. They are so young." Similarly, when talking about her monthly account statements, Liz said, "Yeah, like, oh good. It's grown some more, but it's really, like I said, it's kind of an afterthought. I'm more about in-the-moment type of person so I'm more concerned with day-to-day life."

\subsubsection{Not Expecting Child to Attend College but Demonstrating College-Saver Identity}

The percentage of parents who demonstrate an active college-saver identity (72\%) is higher than the percentage of parents (56\%) who say they expect their child(ren) to attend college. Daphne, a lower-middle-income $(\$ 40,000$ to $\$ 49,999)$ single mother with a 4 -year college degree, is an example of a parent who demonstrates an active college-saver identity but does not expect her daughter to 
attend college. Her doubts appear to stem from her own life experience. When answering a question about whether she expected her daughter to attend college, she stated, "I don't know. I try to take her lead on that." Later in the conversation she provided some insight into why she was uncertain. She said, "I think my biggest thing would be if she, like me, if she met somebody and fell in love, and decided that wasn't a priority anymore." But she still wants to prepare her child for the opportunity to go to college even if she is uncertain about the future. This is evidenced in the following report: "Every year when she starts school we do this board for the first day of school that has her age, her teacher, what she wants to be when she grows up when you take a picture with it." At the same time, HACC provides her with ways to act as though college is close and something her daughter needs to act on now (salience). She said, "We got one [a statement] a couple of weeks ago, and we looked at it together. I showed her you started with $\$ 500$ and now look at that. That's $\$ 900$ and I forget what it was $\$ 900$ something. It's almost $\$ 1000$ for you to use for college, that's a lot of money." The balance in the HACC account also helps Daphne perceive that paying for college is more possible than it would otherwise seem. She connects this money with being able to help pay for college when talking about what HACC does for her and her child: "I like to call it starter money for college, because ... and that it accrues interest. The other thing that I think is cool is that several times a year, they send us I want to use the term coupon.” Rounding out her college-saver identity with an understanding of college and college saving as congruent with her social groups, Daphne also talks with her friends in the community about HACC.

\subsection{Development of a College-Going Culture}

Despite HACC's being relatively new, there is evidence in this sample that it might be helping to develop a college-going culture in Maine. While the formation of an actual culture take many years, what we are looking for in this studies is evidence that such culture may be developing, not that it exists already. As stated in the theory section, an indication of this is when families begin talking about their efforts to recruit others to open accounts and/or encourage them to save for college. An example of this is when Roberto, a middle-class male teacher, said, "I think we've had probably like three friends who've recently had kids and we're like, 'You got to sign up for it.' Like, 'it's free money.'” Another example is Heather, who is talking to people in her extended family about saving for her daughter to go to college:

I would say like I said earlier, just involving everybody. I have a really big family and so I think their ability to sort of already contribute and feel like they are contributing, and I'm trying to move past birthdays that are all presents. Much to my child's sadness, I'm sure, and anger most likely when she turns 5, I want it to be experiences for her and not things, and so I think this contributes to that mentality that like you can plan for her future and 
help us plan for her future, and not having everything just be junk and stuff. It does contribute to that philosophy that my husband and I have. In that way, that's been nice.

At the same time, lack of information or misinformation in some cases may be hindering HACC from reaching its full potential to develop a college-going culture. For example, Hellen said, "Well, I told you that one conversation where I was told-it was actually a daycare provider was telling me that it doesn't go to [pay for] trade schools or community colleges. It only goes to college." She was not sure about the validity of the information but pointed to the lack of information out there concerning the details:

Normally, I would just Google it. I would Google and go from there, but it's not really good. Every time I go to get information it's the same limited information. I see same information all around. It's like trying to get people to just sign up versus actually give you information about what it is. I mean if we end up putting all this money in there, and they don't go to a 4-year college, what happens to it?

However, among this sample of HACC participants, nearly all families spoke about recruiting others into the program or recruiting family members to help save for their child's college education.

\section{Discussion}

Prior to discussing the results of this study, it is important to point out that its most significant limitation is its highly homogenous sample: largely white, educated, middle-class men and women, working as teachers. While this limitation raises significant concerns about the generalizability of these findings. However, the main purpose of this study is not to draw generalizable conclusions; instead, it is descriptive in nature. The authors sought to better understand whether interviews would reveal evidence of a theoretical model, identity-based motivation. Although there is a substantial body of evidence around IBM (for a review, see Oyserman \& Destin, 2010), few studies specifically examine identity-based motivation as a way of better understanding parental educational expectation within CSA programs.

Descriptive findings from this study resemble previous research on the relationship between CSAs and parental educational expectations (Kim et al., 2015). Among the families in this study, 56\% expect their child to graduate from high school and go on to complete some form of postsecondary education. However, when the college-saver identity construct was used to measure parental educational expectations instead of asking parents if they expected their child(ren) to attend college, it rose to $78 \%$.

Our findings suggest that low-income families in HACC describe having positive educational expectations. Some evidence also indicates that for some parents, whether they expect their child to attend and complete college is shaped by 
their child(ren)'s expectations for themselves or in how they are performing in school. For example, Michelle said the following:

And I knew several parents in the area that just didn't do it. And I've often inquired like, "Why would you not do it? It's free money." Why would-I mean that doesn't make sense to me. And they're like, "Well, I don't know if my kid's going to college." Don't agree.

This is similar to the findings of Elliott and Friedline (2013), who found that parents are more likely to contribute to their children's college financing when the child expects to graduate from college. They state, "This suggests that among four-year college goers it remains important for parents that students provide them with a type of insurance that it is safe to invest" (p. 146).

Our results also provide evidence that families in HACC describe developing a college-saver identity. Specifically, these parents mostly expressed a belief that their child is collegebound and that saving is a way to help overcome the difficulty of paying for college. While Elliott, Sherraden, Johnson and Guo (2010) did not examine the effects of CSAs on parents' college-saver identity, they did find evidence that children who were in a CSA program were more likely to perceive savings as a way to pay for college than children in a comparison group.

\section{Conclusion}

Evidence that CSA programs affect parental educational expectations early in a child's life may be particularly significant since the educational expectations of many disadvantaged parents tend to diminish as they confront obstacles to their children's success (Mistry, White, Benner, \& Huynh, 2009). Therefore, intervening before these obstacles can undermine parents' engagement and investment in their children's educational development may be particularly important. For example, researchers have found that mothers' expectations of their preschool children are positively associated with their children's sixth-grade math and vocabulary proficiency (Hess et al., 1984). Entwisle et al. (2005) found that higher expectations among low-income families may be associated with higher college completion rates. In addition, using the IBM framework to understand the relationship between CSA programs and parental expectations may provide a more complete understanding than merely asking parents if they expect their child to attend and complete college. However, it is important to emphasize that this study does not provide conclusive evidence, and more research is needed.

\section{Foundation}

This research was supported by grants from the Harold Alfond Foundation, the John T. Gorman Foundation, and the Charles Stewart Mott Foundation.

\section{Conflicts of Interest}

The authors declare no conflicts of interest regarding the publication of this paper. 


\section{References}

Boshara, R., Clancy, M., Newville, D., \& Sherraden, M. (2009). The Basics of Progressive $529 s$. St. Louis, MO: Washington University, Center for Social Development; Washington DC: New America Foundation.

Child Trends Data Bank. (2015). Parental Expectations for Their Children's Academic Attainment: Indicators of Child and Youth Well-Being. Bethesda, MD.

https://www.childtrends.org/wp-content/uploads/2015/10/115_Parental_Expectations. pdf

CFED. (2016). State of the Children's Savings Field 2016. Washington DC. https://prosperitynow.org/resources/state-childrens-savings-field-2016

Clancy, M., Lasser, T., \& Taake, K. (2010). Saving for College: A Policy Primer. St. Louis, MO: Washington University, Center for Social Development.

Clancy, M., \& Sherraden, M. (2014). Automatic Deposits for All at Birth: Maine's Harold Alfond College Challenge.

https://csd.wustl.edu/Publications/Documents/Maine\%E2\%80\%99s\%20Harold\%20Alf ond\%20College\%20Challenge.pdf

Davis-Kean, P. D. (2005). The Influence of Parent Education and Family Income on Child Achievement: The Indirect Role of Parental Expectations and the Home Environment. Journal of Family Psychology, 19, 294-304.

https://doi.org/10.1037/0893-3200.19.2.294

Department of Numbers (2017). Maine Household Income. https://www.deptofnumbers.com/income/maine/

Elliott, W. (2013). Small-Dollar Children's Savings Accounts and Children's College Outcomes. Children and Youth Services Review, 35, 572-585.

https://doi.org/10.1016/j.childyouth.2012.12.015

Elliott, W. (2015). Building College-Saver Identities among Latino Immigrants: A Two-Generation Prosperity Kids Account Pilot Program (AEDI Report 06-2015). Lawrence, KS: Center on Assets, Education, and Inclusion.

Elliott, W., \& Beverly, S. (2011). The Role of Savings and Wealth in Reducing "Wilt" between Expectations and College Attendance. Journal of Children and Poverty, 17, 165-185.

Elliott, W., \& Friedline, T. (2013). You Pay Your Share, We'll Pay Our Share. Economics of Education Review, 33, 134-153. https://doi.org/10.1016/j.econedurev.2012.10.001

Elliott, W., Constance-Huggins, M., \& Song, H. (2013). Improving College Progress among Low- to Moderate-Income (LMI) Young Adults: The Role of Assets. Journal of Family and Economic Issues, 34, 382-399. https://doi.org/10.1007/s10834-012-9341-0

Elliott, W., Sherraden, M., Johnson, L., \& Guo, B. (2010). Young Children’s Perceptions of College and Saving: Potential Role of Child Development Accounts. Children and Youth Services Review, 32, 1577-1584. https://doi.org/10.1016/j.childyouth.2010.03.018

Englund, M. M., Luckner, A. E., Whaley, G. J. L., \& Egeland, B. (2004). Children's Achievement in Early Elementary School: Longitudinal Effects of Parental Involvement, Expectations, and Quality of Assistance. Journal of Educational Psychology, 96, 723-730. https://doi.org/10.1037/0022-0663.96.4.723

Entwisle, D. R., Alexander, K. L., \& Olson, L. S. (2005). First Grade and Educational Attainment by Age 22: A New Story. American Journal of Sociology, 110, 1458-1502. https://doi.org/10.1086/428444

Finance Authority of Maine (2015). NextGen Triples Amount of Annual Matching Grant. http://www.famemaine.com/blog/post/nextgen_triples_amount_of_ann1.aspx 
Gill, S., \& Reynolds, A. J. (1999). Educational Expectations and School Achievement of Urban African American Children. Journal of School Psychology, 37, 403-424. https://doi.org/10.1016/S0022-4405(99)00027-8

Goldberg, F. (2005). The Universal Piggy Bank: Designing and Implementing a System of Savings Accounts for Children. In M. Sherraden (Ed.), Inclusion in the American dream: Assets, Poverty, and Public Policy (pp. 303-322). New York, NY: Oxford University Press.

Harold Alfond Foundation (2011). HAF 2011 Grant Report. Portland, ME: Harold Alfond Foundation.

http://haroldalfondfoundation.org/pdf/announcements/HAF2011GrantReport_000.pdf

Harold Alfond Foundation (2012). HAF 2012 Grant Report. Portland, ME: Harold Alfond Foundation.

http://haroldalfondfoundation.org/pdf/announcements/2012GrantReport_000.pdf

Harold Alfond Foundation. (2013). HAF 2012 Grant Report. Portland, ME: Harold Alfond Foundation.

http://haroldalfondfoundation.org/pdf/announcements/2012GrantReport_000.pdf

Hess, R. D., Holloway, S. D., Dickson, W. P., \& Price, G. G. (1984). Maternal Variables as Predictors of Children's School Readiness and Later Achievement in Vocabulary and Mathematics in Sixth Grade. Child Development, 55, 1902-1912.

https://doi.org/10.2307/1129937

Horn, L., Chen, X., \& Chapman, C. (2003). Getting Ready to Pay for College: What Students and Their Parents Know about the Cost of College Tuition and What They Are Doing to Find Out. National Center for Education Statistics.

Hossler, D., Schmit, J., \& Vesper, N. (1999). Going to College. How Social, Economic, and Educational Factors Influence the Decisions Students Make. Baltimore, MD: The Johns Hopkins University Press.

Huang, J., Beverly, S., Clancy, M., Lassar, T., \& Sherraden, M. (2013). Early Program Enrollment in a Statewide Child Development Account Program. Journal of Policy Practice, 12, 62-81. https://doi.org/10.1080/15588742.2012.739124

Huang, J., Kim, Y., \& Sherraden, M. (2016). Material Hardship and Children's Social-Emotional Development: Testing Mitigating Effects of Child Development Accounts in a Randomized Experiment. Child: Care, Health and Development, 43, 89-96. https://doi.org/10.1111/cch.12385

Kim, Y., Huang, J., Sherraden, M., \& Clancy, M. (2017). Child Development Accounts, Parental Savings, and Parental Educational Expectations: A Path Model. Children and Youth Services Review, 79, 20-28. https://doi.org/10.1016/j.childyouth.2017.05.021

Kim, Y., Sherraden, M., Huang, J., \& Clancy, M. (2015). Child Development Accounts and Parental Educational Expectations for Young Children: Early Evidence from a Statewide Social Experiment. Social Service Review, 89, 99-137. https://doi.org/10.1086/680014

Loya, R. M., Garber, J., \& Santos, J. (2017). Levers for Success: Key Features and Outcomes of Children's Savings Account Programs. Waltham, MA: Institute on Assets and Social Policy.

Marjoribanks, K. (1984). Ethnicity, Family Environment and Adolescents' Aspirations: A Follow-Up Study. Journal of Educational Research, 77, 166-171. https://doi.org/10.1080/00220671.1984.10885518

Mistry, R. S., White, E. S., Benner, A. D., \& Huynh, V. W. (2009). A Longitudinal Study of the Simultaneous Influence of Mothers' and Teachers' Educational Expectations on 
Low-Income Youth's Academic Achievement. Journal of Youth and Adolescence, 38, 826-838. https://doi.org/10.1007/s10964-008-9300-0

Oyserman, D. (2007). Social Identity and Self-Regulation. In A. Kruglanski, \& T. Higgins (Eds.), Handbook of Social Psychology (2nd ed., pp. 432-453). New York, NY: Guilford Press.

Oyserman, D. (2013). Not Just Any Path: Implications of Identity-Based Motivation for School Outcome Disparities. Economics of Education Review, 33, 179-190. https://doi.org/10.1016/j.econedurev.2012.09.002

Oyserman, D., Bybee, D., \& Terry, K. (2006). Possible Selves and Academic Outcomes: How and When Possible Selves Impel Action. Journal of Personality and Social Psychology, 91, 188-204. https://doi.org/10.1037/0022-3514.91.1.188

Oyserman, D., \& Destin, M. (2010). Identity-Based Motivation: Implications for Intervention. The Counseling Psychologist, 38, 1001-1043. https://doi.org/10.1177/0011000010374775

Oyserman, D., Terry, K., \& Bybee, D. (2002). A Possible Selves Intervention to Enhance School Involvement. Journal of Adolescence, 25, 313-326.

https://doi.org/10.1006/jado.2002.0474

Padgett, D. (2008). Qualitative Methods in Social Work Research (2nd ed.). Thousand Oaks, CA: Sage Publications.

Patton, M. (2002). Qualitative Evaluation and Research Methods. London: Sage.

Pearce, R. R. (2006). Effects of Cultural and Social Structural Factors on the Achievement of White and Chinese American Students at School Transition Points. American Educational Research Journal, 43, 75-101. https://doi.org/10.3102/00028312043001075

Powell, G. (2014). Remarks to the Portland Regional Chamber of Commerce and Announcement of Automatic Enrollment for the Harold Alfond College Challenge. http://www.haroldalfondfoundation.org/pdf/announcements/EggsIssues3.4.14FINAL= 000.pdf

Rowan-Kenyon, H., Bell, A., \& Perna, L. (2008). Contextual Influences on Parental Involvement in College Going: Variations by Socioeconomic Class. The Journal of Higher Education, 79, 564-586.

Sandefur, G. D., Meier, A. M., \& Campbell, M. E. (2006). Family Resources, Social Capital, and College Attendance. Social Science Research, 35, 525-553.

https://doi.org/10.1016/j.ssresearch.2004.11.003

Sherraden, M. (1991). Assets and the Poor: A New American Welfare Policy. Armonk, NY: M.E. Sharpe.

Singh, K., Beckley, P., Trivette, P., Keith, T. Z., Keith, P., \& Anderson, E. (1995). The Effects of Four Components of Parental Involvement on Eighth-Grade Student Achievement: Structural Analysis of NELS-88 Data. School Psychology Review, 24, 299-317.

Zhan, M. (2006). Assets, Parental Expectations and Involvement, and Children's Educational Performance. Children and Youth Services Review, 28, 961-975. https://doi.org/10.1016/j.childyouth.2005.10.008

Zhan, M., \& Sherraden, M. (2011). Assets and Liabilities, Educational Expectations, and Children's College Degree Attainment. Children and Youth Services Review, 33, 846-854. https://doi.org/10.1016/j.childyouth.2010.12.006

Zhang, Y., Haddad, E., Torres, B., \& Chen, C. (2011). The Reciprocal Relationships among Parents' Expectations, Adolescents' Expectations, and Adolescents' Achievement: A Two-Wave Longitudinal Analysis of the NELS Data. Journal of Youth and Adolescence, 40, 479-489. https://doi.org/10.1007/s10964-010-9568-8 